\title{
Eco-labeling is a useful piece of informational metabolism in the youth environment
}

\author{
E. I. Khabarova*, S. V. Nikitina, and M. V. Strebkova \\ MIREA - Russian Technological University (M.V. Lomonosov Institute of Fine Chemical \\ Technologies), Moscow,119571, Russia
}

\begin{abstract}
Environmental awareness of consumers and the popularity of a healthy lifestyle are the trends of our time both in the world and in Russia. The article discusses the ecolabelling sign as a means of offline information about the environmental characteristics of products and an important criterion when choosing and buying various goods. In our country, there are only prerequisites for an approach to greening business and positioning "environmentally friendly" products. However, it is vital that everyone understands the eco-label and distinguishes the certificate of declared quality from the marketing ploy. The paper touches upon the issues of ecological education and formation of the population ecological culture. To clarify the importance of eco-labeling in the formation of an environmentally oriented lifestyle among young people, a sociological research method was used, suitable for clarifying any aspects of social relations and capable of providing operational primary sociological information. The results of the survey of the 1st and 2nd year students of the Moscow State University of Fine Chemical Technologies named after M.V. Lomonosov in 2019/2020 academic year, concerning their interest in the environmental characteristics of the purchased goods, are provided.
\end{abstract}

\section{Introduction}

It is known that at present we are dealing with many changes in all spheres of life, perceiving them as a significant acceleration of the pace of life. Wherein, we are required to be very flexible in our actions. The main thing is that these changes are perceived consciously, in accordance with the real course of events. There can be an adequate response to what is happening only under these conditions [1]. Wherein, the exchange of information with the environment, i.e. the so-called informational metabolism [2,3], is our main vital function, like breathing.

The term "information metabolism" was offered by the Polish psychiatrist and philosopher Anton Kempinski, who compared the biological term of metabolism (a set of processes in the body, as a result of which the incoming food, water and air are converted into substances necessary for the body for life) with the process of perception, accumulation, assimilation, processing, storage and transmission of information by the human psyche. According to his theory, external information signals are likened to food, being transformed

${ }^{*}$ Corresponding author: khabarova@mitht.ru 
and perceived by certain channels of the human psyche, and also (depending on the quantity and quality of this information) significantly affecting the mental health of each person.

All information we perceive affects our thinking and behavior. Everything that we see, hear and feel penetrates into us and affects our life. Now in the information age, the quality of the information that we receive is extremely important. Even if we are dealing with reliable, not falsified information coming to us from the environment, we need a lot of work to analyze information, process it and select the most beneficial adaptive behavior [1].

Most of the information that is widely available today for every citizen for private use is used to create a variety of benefits. The only question is whether we know how to handle this information in such a way that it benefits us, not harm.

According to international studies, there are two important for us among ten trends in demand that are relevant today. The first one is environmental awareness of consumers, the second is the popularization of a healthy lifestyle. In Russia, it is still not easy to implement the idea of the need to keep track of what goods we use, and to think not only about ease of use, but also about how this or that product was produced and how it shall be disposed of. Wherein, the demand for eco-friendly products has grown significantly in recent years: now buyers are ready to pay about $30 \%$ more for products, if they belong to the "eco" category, the population begins to simply care more about their own health, and in fact, at the same time, about preserving environment. Eco-labels and other symbols on products are intended to inform the user about the environmental effects of products, production processes or safety for consumer health [4].

The eco-label is awarded only to those manufacturers who have successfully passed the examination and, accordingly, have proven the environmental safety and high quality of their products. At this stage, mainly large world-class companies can meet international environmental safety criteria, for which reducing the negative impact on the environment becomes a real competitive advantage.

Due to above, the goal of environmental education and upbringing is not to preserve the world in its original form, but to find forms of harmonious co-evolution of Man and Nature, which would ensure the joint development of the biosphere and human population, which is an integral part of the biosphere [5].

Therefore, ecological education is formation among the general population of the consistency of all types of human activity that are associated with the knowledge, development and transformation of nature. Wherein, educational and upbringing tasks are not limited only to formation of a sense of respect for nature, but also consist in deepening and expanding environmental knowledge.

The biosphere consciousness and worldview can provide the basis for reasonable cooperation between man and the natural environment.

Environmental consciousness (an indispensable component of environmental culture) is understood as the result of the logical processing of knowledge, which turns this knowledge into beliefs, value orientations and attitudes of people, as well as stimulating the cognitive activity of citizens in order to improve the natural environment.

Wherein, the ecological worldview is considered as a multidimensional integral component of the intellectual and spiritual culture of the individual, as a subjective, systemic, multidimensional experience of the individual, which ensures his/her creative self-realization in understanding and resolving environmental problems [6].

That is why for our society, where the number of problems requiring careful sociological study is growing, the public engagement of sociology is becoming actual. The public and the authorities often do not notice many sociological conclusions about modern challenges and threats (including environmentally oriented ones), as well as the offered ways and recommendations for overcoming them considering the methods of forecasting and constructing options for situation development. In this regard, it is necessary to update 
communication channels through the media considering not only paper, but also electronic media, the Internet and other discussion platforms [7, 8].

When comparing three methods by which sociological study is usually carried out (sociological survey, the method of observation and the study of documentary information in all forms), preference was given not to the theoretical method of analysis, but to empirical study, which is aimed at obtaining general information about human actions in all kinds of arising situations [9].

In order to reveal what young people think about certain positions, it is possible to collect the information necessary for study by conducting a sociological survey (one of the best and most reliable study methods) based on the principle of randomness with involvement of a large number of people. Additional advantages of this method are cost-effectiveness, efficiency, mobility, simplicity and direct contact with the respondent of the received information array. These data will concern the collective, group, public and, of course, the purely individual opinion of each person participating in the experiment. Today, using a sociological survey, it is possible to obtain more than $90 \%$ of sociological data [10].

Via the efforts of the All-Russian Center for the Study of Public Opinion (VTs5I9OM) and other organizations, public opinion polls are conducted regularly in our country. It was found that $78 \%$ of the respondents believe that such polls help the authorities to learn about the mood in society, and $52 \%$ report that the results of the polls are useful to scientists who study social processes [11].

Document "Agenda of the 21 century" adopted at the UN Conference on Sustainable Development (1992) (Chapter 4, para. 21) states that "Governments, in cooperation with the industrial sector ... need to encourage the expansion of information programs that provide for introduction of environmental labeling of goods and dissemination of information about the environmental characteristics of the products sold so that buyers can make informed choices about certain products" [12].

Accordingly, the ecological component of sustainable development shall orient society towards maintaining the sustainability of ecosystems, protecting the environment and adopting an environmentally oriented lifestyle by citizens, accompanied not only by a clear understanding of environmental problems and threats, but also by rejection of the consumerutilitarian attitude to the environment [13].

Unfortunately, it is too early to talk about the wide distribution and great popularity of ecolabels in Russia. However, in fairness, it shall be noted that already now in our country there are many legal acts that affect the need to improve the quality of product production: regulations in the field of consumer protection, environmental protection, standardization and advertising, as well as state standards and the conformity mark of Gosstandart of the Russian Federation [14].

\section{Materials and Methods}

RTU MIREA teachers are also trying to introduce the useful concept of eco-labeling into the everyday life of student buyers. Socio-statistical diagnostics also helps to obtain information about the impact of environmentally oriented transformations on young people.

Supporting the development of "a targeted system of general and continuous environmental education and upbringing that shall be based on the principles of consistency, continuity, integrity, complexity and interdisciplinarity" [15], we considered it expedient to conduct regular sociological surveys in the form of written questionnaires among junior students of RTU MIREA and high school students in the Western District of Moscow regarding awareness of environmental labeling signs $[16,17]$. 
In the context of our study, we wanted to convince young people of the need to balance environmental issues and their primary needs as consumers of the goods and services provided to them.

\section{Results and Discussions}

The results of an anonymous questionnaire survey (self-filling of questionnaire forms) of 229 1st year students and 222 2nd year students for 2019/2020 full-time education at the Moscow State University of Fine Chemical Technologies named after M.V. Lomonosov are shown in Fig. 1-10. The total number of respondents was 451 people.

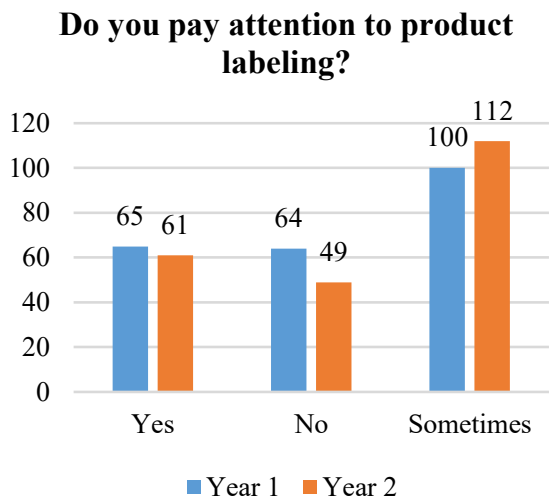

Fig. 1. Answers to question No. 1

\section{Did you know that the product and its packaging can harm human health and the environment?}

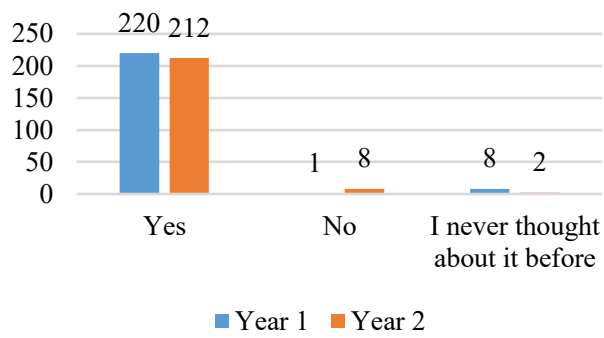

Fig. 2. Answers to question No. 2

Do you carefully study the information on the package?

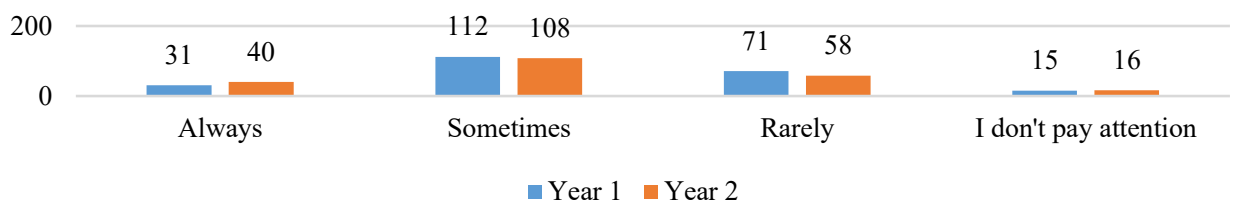

Fig. 3. Answers to question No. 3 


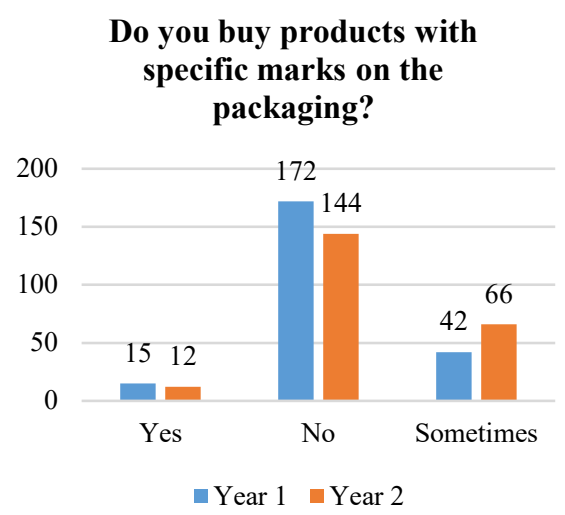

Fig. 4. Answers to question No. 4

\section{Do you know what an eco-label} is?

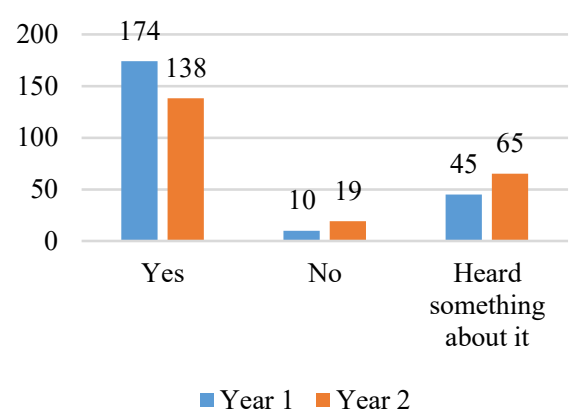

Fig. 5. Answers to question No. 5

\section{What markings do you pay attention to?}

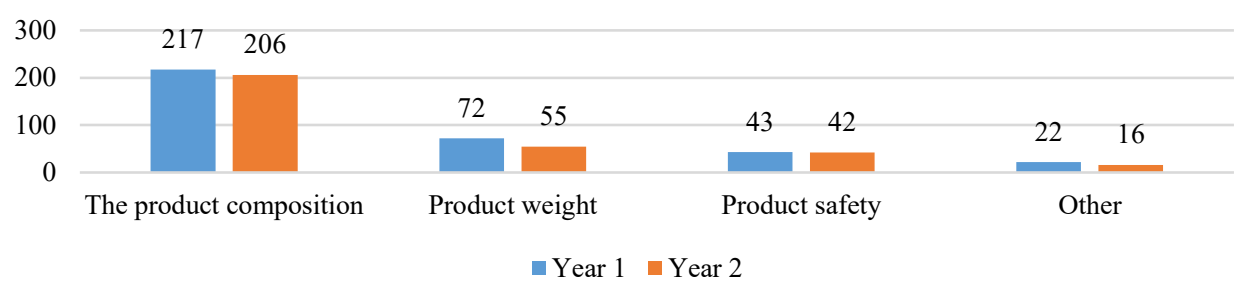

Fig. 6. Answers to question No. 6

Do you pay attention to ecolabeling when buying a product?

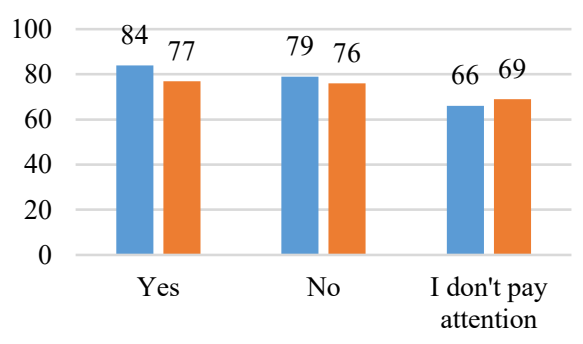

- Year 1 Year 2
Do you know about the appearance in Russia of stores or departments in stores selling exclusively ecological products?

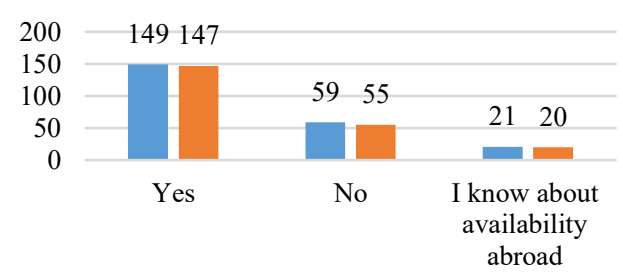

- Year 1 Year 2

Fig. 7. Answers to question No. 7

Fig. 8. Answers to question No. 8 


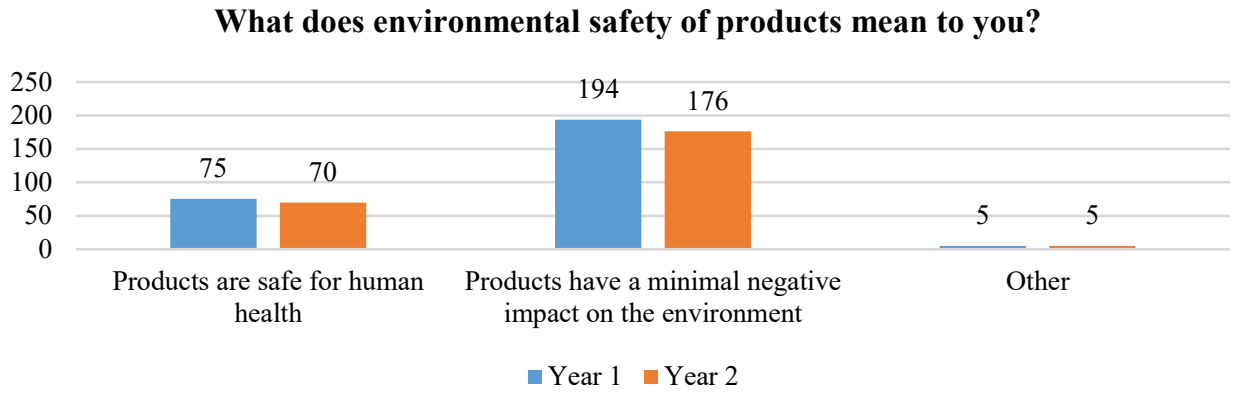

Fig. 9. Answers to question No. 9

\section{Are you ready to buy environmentally friendly products, even if they are more expensive than usual?}

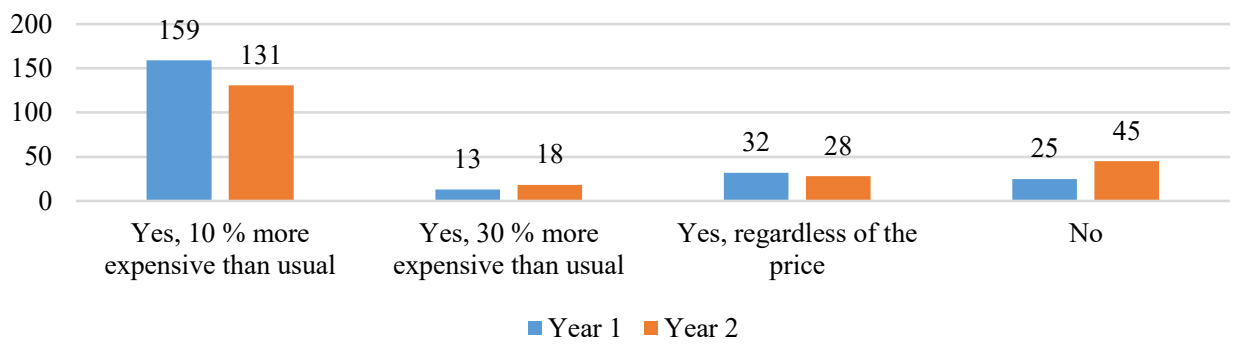

Fig. 10. Answers to question No. 10

\section{Conclusions}

From the results of the questionnaire, it can be seen that:

1) all answers of the 1 st and 2nd year students are generally comparable to each other (in percentage);

2) half of the respondents are not attentive to the labels containing information about the purchased goods, and only occasionally study them;

3 ) the same $50 \%$ practically do not pay attention to such labeling of goods on labels as warning notices intended to ensure the safety of the consumer and the environment, and are guided, most likely, only by the basic consumer properties (weight characteristic, country and manufacturer, term suitability, methods of transportation and storage, etc.);

4) wherein, the majority of respondents (almost $100 \%$ ) are really aware that any product and its packaging can harm human health (35\% think) and the environment (70\% think);

5) $80 \%$ of students were directly familiar with the word "ecolabelling", although in life they ignore goods with specific signs on the packaging: only $40 \%$ admitted that they pay attention to ecolabels when buying a product.

6) About $80 \%$ know or have heard of appearance in Russia of stores or departments in stores selling exclusively ecological products.

7) Interestingly that $70 \%$ of the respondents are prone to buy environmentally friendly products $10 \%$ more expensive than usual, and $10 \%$ - even regardless of the price. 
Although in this study the results of a sociological survey represent only a vector for measuring certain values, the conversation is about formation of adequate environmental values and types of everyday behavior that correspond to the goals and principles of sustainable development of society, i.e. harmonious relationship with nature.

Interviewing junior students has 2 goals:

1) focusing the attention of students, as consumers of products and services, on presence of labels with ecolabels on goods, as a result of which young people are armed with accessible information that allows them to make a choice in favor of high-quality products considering the minimum negative impact on the environment in the process of their production;

2) formation of a forward movement in any trajectory of teaching today's students, as tomorrow's entrepreneurs and leaders, on coordination of used and implemented technologies with identification of the focus of the future target activities of today's students and tomorrow's entrepreneurs on coordination of the interests of society and nature from the standpoint of introduction and use of technologies friendly to the ecosphere.

\section{References}

1. B. Krieger, Slavyane, 2(11), 32-35 (2018)

2. A. Kempinsky, Existential Psychiatry, 320 (Sovershenstvo, 1998)

3. A. Kempinsky, Melancholy, 405 (Nauka, 2002)

4. A. G. Ishkov, V. A. Grachev, Popular Ecology, 196 (NEF named after V.I. Vernadsky, 2014)

5. N. N. Moiseev, Human ecology through the eyes of a mathematician, 251 (Molodaya Gvadiya Publishing House, 1988)

6. N. M. Mamedov, S.N. Glazachev, Environmental education: concepts and technologies: Collection of scientific papers, Volgograd, 16-26 (1996)

7. L. N. Vdovichenko, Sociological studies, 2, 134-140 (2014)

8. L. N. Vdovichenko, Sociological Studies, 7, 25-29 (2015)

9. Sociological research, Research agency ZOOM MARKET, https://www.mazm.ru/

10. E. Potapova, Sociological survey: an example. The results of a sociological survey, Project FB.ru, https://fb.ru/

11. I. Zakharov, 10 most interesting opinion polls in Russia 2018-2019, Site BASETOP, https://basetop.ru/

12. Agenda for the XXI century, http://www.un.org/

13. I. A. Sosunova, L. G. Titarenko, Use and protection of natural resources in Russia, 4(142), 99-102 (2015)

14. A. N. Kazantseva, O. I. Malikova, Innovations, 4(210), 71-75 (2016)

15. S. N. Glazachev, E. A. Kogay, Environmental culture and education, 34 (Horizont, 1999)

16. L. L. Budaeva, S. V. Nikitina, E. I. Khabarova, Understanding ecolabels that reflect relevant environmental information in a consumer-accessible form, from college students. Materials of the VI All-Russian scientific-practical. conference "Environment and Health. Hygiene and ecology of urbanized areas", Moscow, September 13-14, 99103 (2016) 
17. E. I. Khabarova, S. V. Nikitina, L. L. Budaeva, M. V. Strebkova, A. M. Pogorely. Assistance in introducing environmental culture through familiarity with eco-labels. // Life Safety: Problems and Solutions, 2018, Collection of articles based on the materials of the II Int. scientific and practical. conferences. Under the general ed. of S.F. Sukhanovoy, Kurgan: publishing house of KGSKhA named after T.S. Maltsev, 2018, pp. 220-223. 